\title{
Stock Market Development and Real Economic Activity in Peru
}

\author{
Erick Lahura* Marco Vega* \\ * Banco Central de Reserva del Perú
}

\author{
DT. N²014-022 \\ Serie de Documentos de Trabajo \\ Working Paper series \\ Diciembre 2014
}

Los puntos de vista expresados en este documento de trabajo corresponden a los autores y no reflejan necesariamente la posición del Banco Central de Reserva del Perú. 


\title{
Stock Market Development and Real Economic ACTIVITY IN PERU
}

\author{
ERICK LAHURA AND MARCO VEGA*
}

(September, 2014)

\begin{abstract}
We explore the causal effect of stock market development on real economic activity in Peru. Based on the predictions of a simple growth model, we estimate vector autoregressive models and identify stock market shocks by imposing long-run restrictions in the dynamic response of real output per capita. Using annual time series data for the period 1965-2013, we find that stock market shocks have had a short-run causal effect on real GDP per capita only after 1991, a result that is consistent with standard Granger causality tests; however, the contribution of stock market shocks to output growth dynamics have been small. Thus, policy actions aimed at further developing the Peruvian stock market may have a positive impact on the dynamics of economic growth.
\end{abstract}

JEL Classification: E23, G1

Keywords: Stock market development, output growth, VAR, long-run restrictions.

*Erick Lahura: Central Reserve Bank of Peru, and Pontificia Universidad Católica del Peru (erick.lahura@bcrp.gob.pe). Marco Vega: Central Reserve Bank of Peru, and Pontificia Universidad Católica del Peru (marco.vega@bcrp.gob.pe). We thank participants of the conference "Dynamics, Economic Growth, and International Trade, DEGIT XVIII" organised in Lima, Peru (September 26-27, 2013) for helpful comments. A previous version of this paper circulated under the title "The dynamic relationship between stock market development and real economic activity: Evidence from Peru, 1965-2011". 


\section{Introduction}

How important are stock markets in the dynamics of real economic activity? Do they have any causal effect or do they just help to predict economic growth? In this paper we intend to answer these questions by exploring the empirical relationship between stock market development and real economic activity using time series data. We focus on Peru, a developing economy with a stock market at an early stage of development.

Since Smith (1776), the relationship between the financial system and real activity has been widely studied from a theoretical and empirical point of view. ${ }^{1}$ Although there is still no consensus on the causal relationship, it is well accepted in the literature that stock markets and banking systems allow societies to optimally channel resources from savings towards consumption and productive activities. Even though the main emphasis has been on banks (e.g. Bagehot, 1873; Schumpeter, 1912, among others), stock markets have been acknowledged as an important force in the economy especially since the Great Depression.

On the theoretical side, Levine (1991), Devereux and Smith (1994), and Obstfeld (1994) provide models in which liquid and internationally integrated stock markets may contribute to economic growth. Empirically, the relationship between stock markets and real activity has been studied using different econometric techniques suitable for cross-sectional data (Levine and Zervos, 1998; Cooray, 2010, and references therein), panel data (Henry, 2000; Beck and Levine, 2004; Gupta and Yuan, 2009, and references therein), and time series data (Arestis et al., 2001; Caporale at al., 2005; Enisan and Olufisayo, 2009; Marques et al., 2013, and references therein). In the latter case, the literature has focused on the empirical causality, i.e. time precedence, based on Granger causality tests and VAR analysis. However, efforts to identify the possible causal effect of stock market indicators on real activity have been scant in time series studies.

In this paper, we go beyond the study of empirical causality and try to identify the possible causal effect of stock markets on real economic activity. This is important from a policy perspective because, as stated by Cochrane (1994), only responses to an exogenous variable can measure the effects of policy-induced changes in that variable. Based on the estimation of vector autoregressive models (VARs), we propose the identification of an approximate measure of stock market shocks using long-run restrictions, as proposed by Blanchard and Quah (1989) and applied by Quah and Vahey (1995) in the monetary-macro literature. In particular, a stock market shock is identified as a structural innovation that has no long-run effect on real GDP per capita. This identification strategy is supported by a simple exogenous growth model we develop in this paper, which predicts that in a developing economy an exogenous permanent change in stock market development does not have any long-run effects on real output per capita. Furthermore, the identification strategy is also consistent with the main stylised facts of the Peruvian economy.

\footnotetext{
${ }^{1}$ Some recent surveys include Gertler (1988), King and Levine (1993), Becsi and Wang (1997), and Levine (2005)
} 
Following the literature on this topic, we use annual data for real GDP per capita ${ }^{2}$ and three conventional indicators of stock market development: volume traded to GDP ratio, stock market capitalization to GDP ratio, and the turnover ratio. Although the sample contains only 49 observations (annual data for the period 1965-2013), the span is sufficiently long for time series analysis based on vector autoregressions (see e.g. Demetriades and Hussein, 1996; Ang and McKibbin, 2007), and the application of unit root and cointegration tests (see e.g. Campbell and Perron, 1991; Stock, 1994).

The results show that the dynamic relationship between real GDP per capita and the stock market in Peru has changed over time and that stock market shocks have had a short-run causal effect on real GDP per capita only after 1991, a result that is consistent with standard Granger causality tests; in particular, a one-standard deviation shock to value traded/GDP, turnover and capitalization/GDP increases real GDP per capita after one year by $1 \%, 1.4 \%$ and $1.0 \%$, respectively. However, the contribution of stock market shocks to output growth dynamics has been small. Therefore, the results imply that policy actions aimed at further developing the Peruvian stock market (e.g. promoting a higher participation of both lenders and borrowers, and reducing transaction costs) may have a positive impact on the dynamics of economic growth. These results are robust to the inclusion of other important variables for the Peruvian economy, such as the banking sector development and terms of trade.

The rest of the paper is organised as follows. Section 2 describes the data and the key stylised facts related to the Peruvian stock market. Section 3 presents a simple model of exogenous growth where the interaction between stock market development and capital accumulation depends on the degree of economic development. Section 4 describes the empirical methodology proposed to identify a stock market shock. Section 5 presents and discusses the econometric results, and section 6 concludes.

\section{Data and stylized facts}

The data frequency is annual and covers the period 1965-2013. Based on printed versions of the Superintendency of Security Markets' Annual Reports and its online database ${ }^{3}$ we constructed three conventional indicators of stock market development: (i) value traded to GDP ratio, (ii) turnover ratio, and (iii) stock market capitalization to GDP ratio (available only for the period 1990-2013). Real GDP per capita, ${ }^{4}$ bank credit to GDP ratio, ${ }^{5}$ and terms of trade were obtained from the Central Reserve Bank of Peru's online database.

Value traded/GDP and turnover are indicators of stock market liquidity. Value traded is defined as the value of shares traded in the stock market, whereas turnover is defined as the percentage of traded shares relative to total shares valued in the stock

\footnotetext{
${ }^{2}$ This indicator can be considered as an average measure of welfare and development.

${ }^{3}$ Before 2012, the SMV was called the National Commission of Securities (CONASEV).

${ }^{4}$ We use real GDP per capita so that its growth rate is an approximate measure of welfare

${ }^{5}$ This is a standard indicator of banking sector development.
} 
market. A higher value traded/GDP or turnover indicates a more liquid and developed stock market, which provides potential benefits for real economic activity and growth. Theoretically, illiquid markets could prevent long-run investments because it is difficult to sell shares whenever an investor needs liquidity. However, a lower turnover could also indicate that investors have a long-term investment horizon (e.g. insurance companies and private pension funds), which could contribute to economic growth. Stock market capitalization is defined as the value of shares that are available in the Lima Stock Market. Thus, a higher capitalization/GDP is also interpreted as an indicator of a bigger and more developed stock market; however, a higher number shares listed does not necessarily affect real activity and growth.

Table 1 shows the evolution of the Peruvian stock market ${ }^{6}$ measured by the average value traded/GDP, capitalization/GDP and turnover for different samples. In average terms, value traded showed an important improvement since 1991, whereas turnover displayed a downward trend during the same period; stock market capitalization also shows an important improvement between 1991 and 2013. However, compared to developed economies like the United Kingdom (UK) and the United States of America (US), it is evident that the Peruvian stock market is at an early stage of development. For instance, according to the Global Financial Development Database, during the period 2001-2013: (i) capitalization/GDP in the UK and US were $127 \%$ and $123 \%$, respectively, whereas in Peru it was $56.8 \%$, (ii) value traded/GDP in UK and US were $171 \%$ and $255 \%$, respectively, whereas in Peru it was $5.1 \%$, and (iii) turnover in UK and US were $138 \%$ and $208 \%$, respectively, whereas in Peru it was $6.5 \%$.

Table 1. Average levels of stock market indicators (\% of GDP)

\begin{tabular}{cccc}
\hline \hline & Value traded & Turnover & Capitalization \\
\hline $\mathbf{1 9 6 5 - 1 9 7 0}$ & 0.2 & 42.5 & n.a. \\
$\mathbf{1 9 7 1 - 1 9 8 0}$ & 0.4 & 82.8 & n.a. \\
$\mathbf{1 9 8 1 - 1 9 9 0}$ & 0.5 & 69.6 & n.a. \\
$\mathbf{1 9 9 1 - 2 0 0 0}$ & 8.4 & 34.0 & 19.5 \\
$\mathbf{2 0 0 1 - 2 0 1 3}$ & 5.1 & 6.5 & 56.8 \\
\hline \hline
\end{tabular}

Figure 1 shows the evolution of stock market indicators along with real GDP per capita (in logs), both in levels and in first differences, from which it is possible to distinguish two periods in the evolution of real GDP per capita. The first period goes from 1965 to 1990 and is a period of stagnation, featuring an important drop in 1983 as a consequence of a weather phenomenon called "El Niño", and between 1988 and 1989 due to the Peruvian hyperinflation episode. The second period starts in 1991 and shows a process of economic recovery that was interrupted between 1998 and 2001, which coincides with international crises (Asia, Russia, Brazil) and domestic political instability

\footnotetext{
${ }^{6}$ The Peruvian stock market was established on December 31st, 1860 (during the government of Ramon Castilla), under the name of Commerce Stock in Lima, and began to operate on January 7th, 1861. After the Great Depression and the Second War World, the New Commerce Stock of Lima was created in 1951. The current Stock Exchange Market of Lima was established in 1970, the same year that the National Commission of Securities (CONASEV) began to operate.
} 
in Peru (between 2000 and 2001), and experienced a slowdown in 2009 as a result of the international financial crisis.

Figure 1. Stock market indicators and output per capita: levels and first-differences.

(a) levels
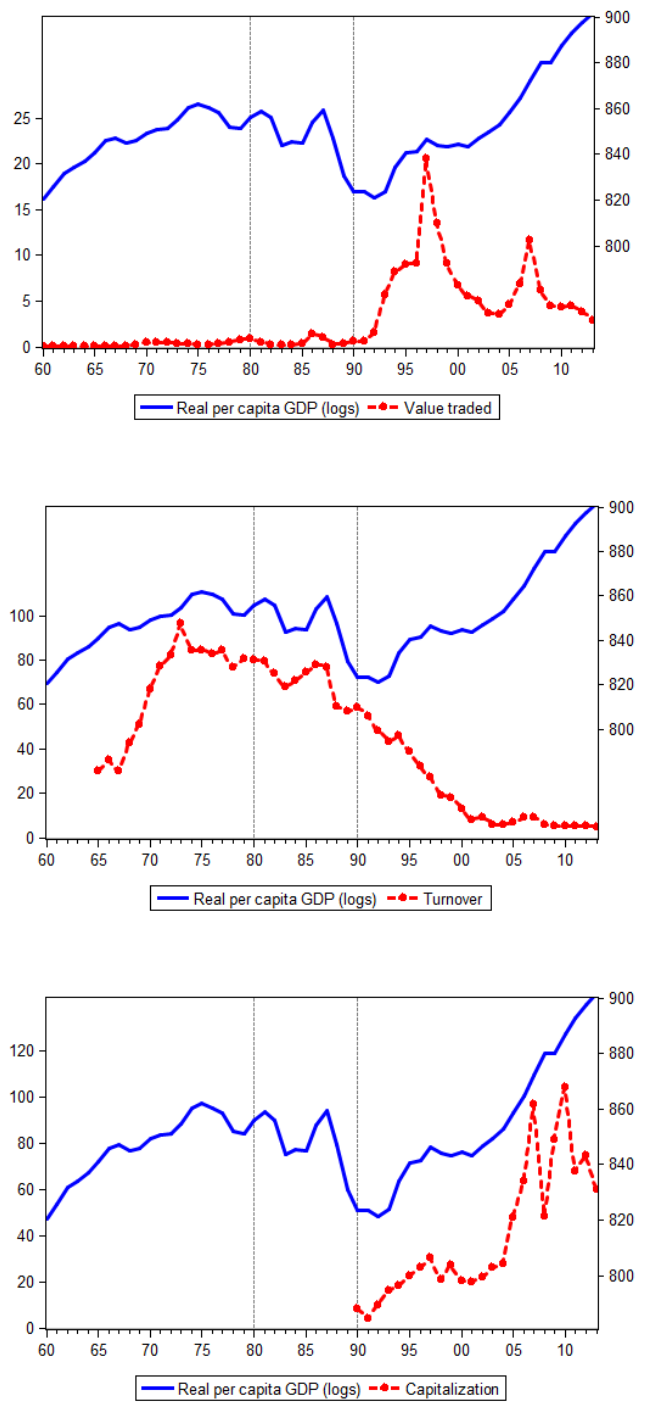

(b) differences
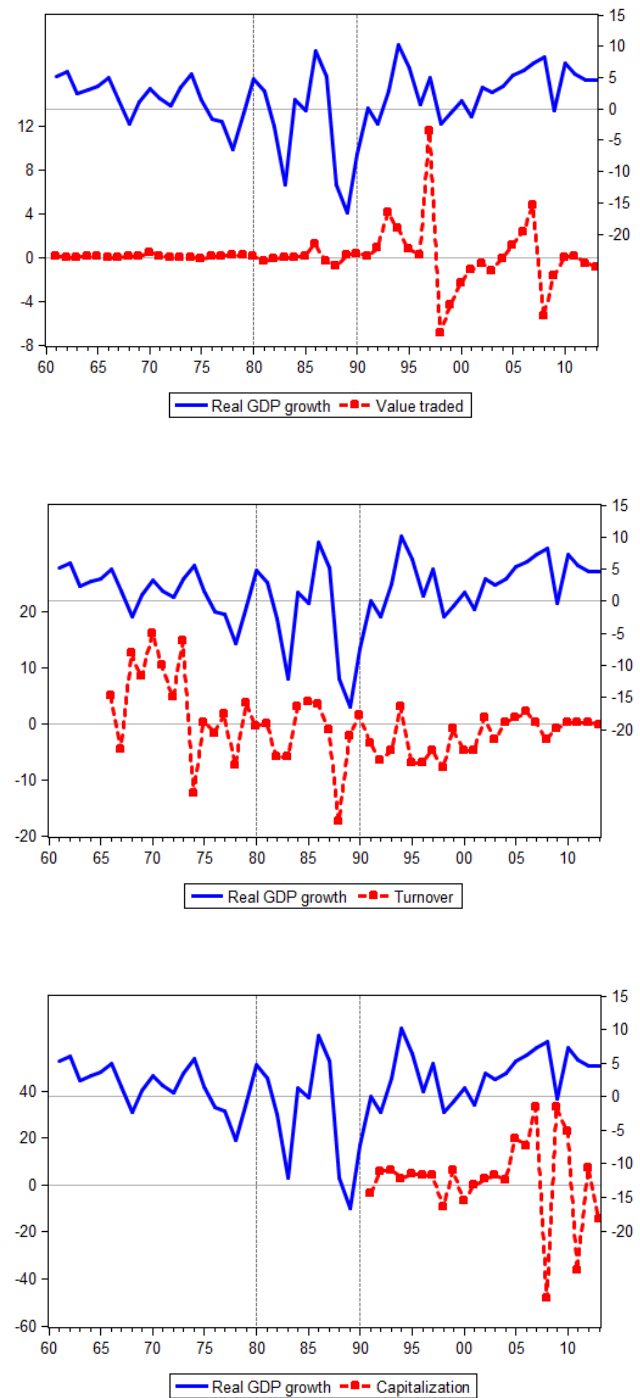

Note: Figures in column (a) illustrate the levels of the series, whereas the ones in column (b) illustrate the first difference of the series. Real GDP per capita is measured on the right axis and is expressed in logarithms and multiplied by 100, so the first difference is expressed in percentages. Stock market indicators are measured on the left axis and are expressed in percentages, so its first difference is measured in percentage points.

On the other hand, the three indicators of stock market development show different performances. The establishment of the National Commission for Companies and Securities (CONASEV) and the Stock Market Regulation Law in 1970 contributed to increasing the number of shares negotiated in the Lima Stock Exchange during the 1970's and 1980's. The stock market liquidity, as measured by value traded/GDP, showed a 
stable performance up to 1990, except for an important drop in 1988 that coincides with the beginning of the hyperinflation period. Even though stock market liquidity improved, its average level was $0.5 \%$ of GDP between 1980 and 1990, a very low level when compared with other Latin American countries (by 1990, Chile registered 2.5\%, Brazil 1.2\%, and Mexico 4.6\%). After the macroeconomic stabilization programme implemented in 1990, which included the financial liberalization of the economy, stock market liquidity started to increase, reaching levels of around 10\% of GDP. However, it has followed an irregular path since 1997, featuring an important increase in 1993 when the Private Pensions Fund Administrators (AFPs) started to operate, and two important drops between 1997-1998 and 2007-2008 related to the Asian crisis and the global financial crisis, respectively.

Turnover suggests a different evolution of liquidity. It shows a downward trend since the beginning of 1970's until the end of the century, which is consistent with the era of financial repression up to 1991. The story from 1991 onwards remains a puzzle. Given that this period coincides with the advent of the AFPs, which collectively have turned out to be the most important investor in the stock market, low stock market liquidity can be explained by the fact that AFPs tend to hold more long-run positions or due to the particular structure of the pension fund market. ${ }^{7}$ Also, important limits to short selling that exist in the Lima stock market (Diaz-Martinez and Fragniere, 2012), might be associated with its low level of liquidity. ${ }^{8}$

Finally, the size of the market, as measured by stock market capitalization to GDP ratio, has shown an upward trend for the available sample 1990-2013. This performance is consistent with the financial liberalization of the economy that began in 1990 and the evolution of real GDP per capita, which led to a peak in capitalization/GDP in 2007 and its subsequent recovery after a major drop in 2008 during the peak of the global financial crisis.

Overall, the data suggest that the Peruvian stock market has improved in terms of liquidity and size especially since 1991. However, it is evident that the Peruvian stock market is still at a developing stage.

\section{A simple model for stock market development and economic growth}

Consider a reduced-form model that describes the dynamic relationship between stock market development, $m(t)$, and capital per capita, $k(t)$. Following the standard neoclassical growth model, output per capita $y$ depends only on capital per capita through a well-defined production function, $f(\cdot)$. However, stock markets may also contribute to the level and dynamics of output per capita by interconnecting more efficiently savers

\footnotetext{
${ }^{7}$ See for example Arrau (2001) for the explanation of the reduction of liquidity in Chile linked to the pension fund market

${ }^{8}$ Evidence provided for example by Daouk and Charoenrook (2005) suggests that absence of short selling is linked to illiquid markets.
} 
and entrepreneurs and thus smoothing capital investment. At early stages of economic development, stock markets might have a small participation in the economy ${ }^{9}$ and thus their contribution to output might be small. However, capital markets may become an important source of funding as the economy develops, and thus the level of stock market development may contribute to economic growth by financing activities that improve output per capita and growth. Based on this idea, we assume that stock market development may positively affect the level of output per capita only when the level of stock market development $m(t)$ is above a given threshold $\bar{m}$. In this case, technology can be expressed as:

$$
y= \begin{cases}f(k(t), m(t)) & , \text { if } m(t)>\bar{m} \\ f(k(t)) & , \text { if } m(t)<\bar{m}\end{cases}
$$

where $\partial f(\cdot) / \partial m(t)>0, \partial f(\cdot) / \partial k(t)>0, \partial^{2} f(\cdot) / \partial m(t)^{2}<0, \partial^{2} f(\cdot) / \partial k(t)^{2}<0$, and $\partial^{2} f(\cdot) / \partial m(t) \partial k(t)>0$. When $m(t)>\bar{m}$ we say that the economy is developed, whereas $m(t)<\bar{m}$ corresponds to a developing economy. Notice that $m(t)$ can be thought as representing not only stock markets but financial markets, i.e. both banking system and stock markets. With respect to capital per capita $k_{t}$, we assume that capital per capita accumulates as in the Solow growth model:

$$
\dot{k}(t)= \begin{cases}s f(k(t), m(t))-\delta k(t) & , \text { if } m(t)>\bar{m} \\ s f(k(t))-\delta k(t) & \text {,if } m(t)<\bar{m}\end{cases}
$$

where $\partial \dot{k}(t) / \partial m(t)>0$ and $\partial \dot{k}(t) / \partial k(t)$ can be either positive or negative. Figure 2 illustrates the locus for $\dot{k}(t) / k(t)=0$ and the dynamics around it for both a developing and a developed country (Figures $2 \mathrm{a}$ and $2 \mathrm{~b}$, respectively). In a developing economy, an increase in capital per capita above its steady-state level $k^{*}$ implies that capital dynamics will drive capital back to $k^{*}$, i.e. $\partial \dot{k}(t) / \partial k(t)>0$ when $k(t)>k^{*}$, whereas capital will fall when the opposite occurs, i.e. $\partial \dot{k}(t) / \partial k(t)>0$ when $k(t)<k^{*}$. In a developed economy, on the other hand, a higher level of stock market development $m(t)$ implies an increase in capital per capita $k(t)$.

The dynamics of stock market development, $\dot{m}$, are assumed to depend on $m(t)$ and $k(t)$, i.e. $\dot{m}=h(m(t), k(t))$, both in developing and developed economies. Higher capital per capita improves income and thus stimulates the development of capital markets, i.e. $\partial \dot{m}(t) / \partial k(t)>0$. Furthermore, we assume that $\partial \dot{m}(t) / \partial m(t)<0$ so that $m(t)$ shows mean reversion. ${ }^{10}$ Figure 3 shows the locus for $\dot{m}(t)=0$ and the dynamics around it.

\footnotetext{
${ }^{9}$ In this scenario, the banking system is the main source of funding in the economy.

${ }^{10}$ If $\partial \dot{m}(t) / \partial m(t)>0$, then the resulting system will display a saddle-path stability. In this case, the effects of an exogenous change in $m(t)$ will be the same but the dynamics towards the new equilibrium will be determined by a unique stable arm.
} 
Figure 2. Locus $\dot{k}(t)=0$

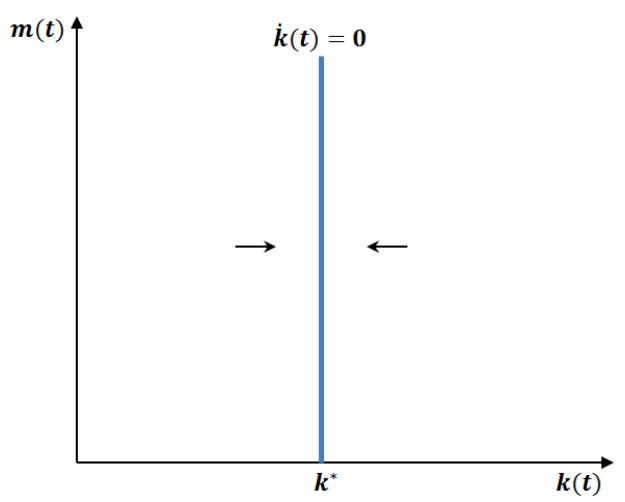

(a) Developing economy

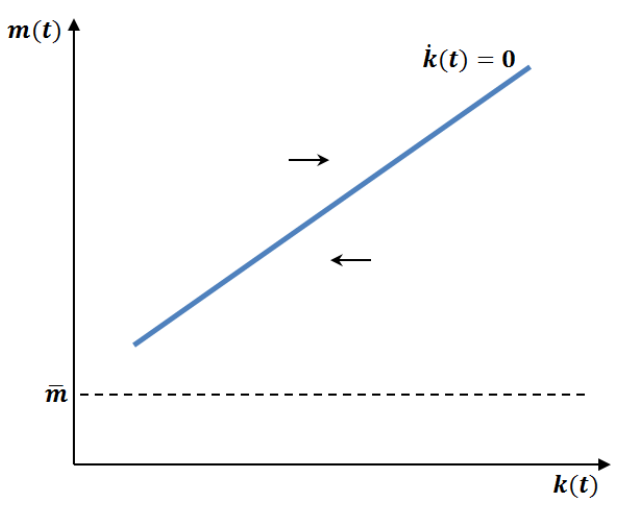

(b) Developed economy

NoTE: $m(t)$ is stock market development and $k(t)$ is capital per capita.

Figure 3. Locus $\dot{m}(t)=0$

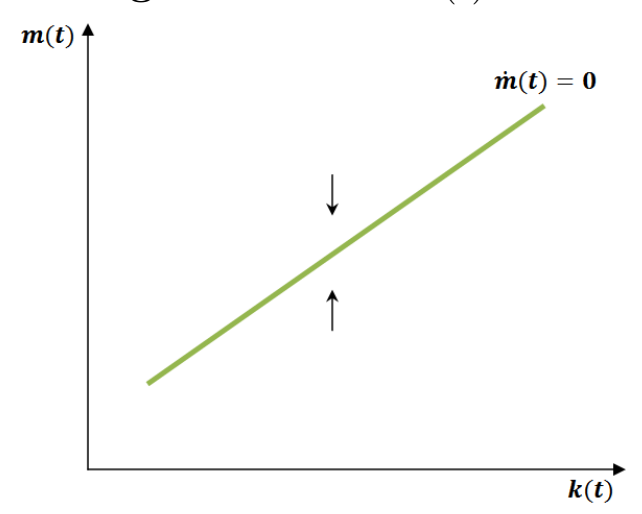

NoTE: $m(t)$ is stock market development and $k(t)$ is capital per capita.

Figures 4 and 5 illustrate the dynamics around $\dot{m}(t)=0$ and $\dot{k}(t)=0$ for the case of a developing and a developed economy, respectively. For the case of a developing economy, Figure 4a shows that the dynamics implied by the model produces a globally stable system. In this scenario, a permanent shock that shifts the curve $\dot{m}(t)=0$ does not have any permanent effect on the level of output per capita. For instance, an exogenous improvement in capital markets technology $h(\cdot)$, which shifts the curve $\dot{m}(t)=0$ to the left as in Figure 4b, implies that a given level of capital per capita has better access to the domestic stock market; this happens, for instance, when a firm can issue more equities and shares that can be traded in the stock market, or more firms can have access to stock markets. In a developing economy, however, it is possible that this improved access does not stimulate higher capital accumulation because of institutional rigidities, lack of confidence, among other reasons, especially at early stages of economic development. Therefore, the steady state level of capital per capita does not change but the stock market development achieves a higher steady-state level, $\left[m^{*}\right]^{\prime}$. In contrast, an exogenous change that shifts the curve $\dot{k}(t)=0$ to the right, e.g. an increase in productivity, increases the steady-state of both stock market development and capital 
per capita, and therefore the steady-state level of output per capita.

Figure 4. Dynamic system for a developing country

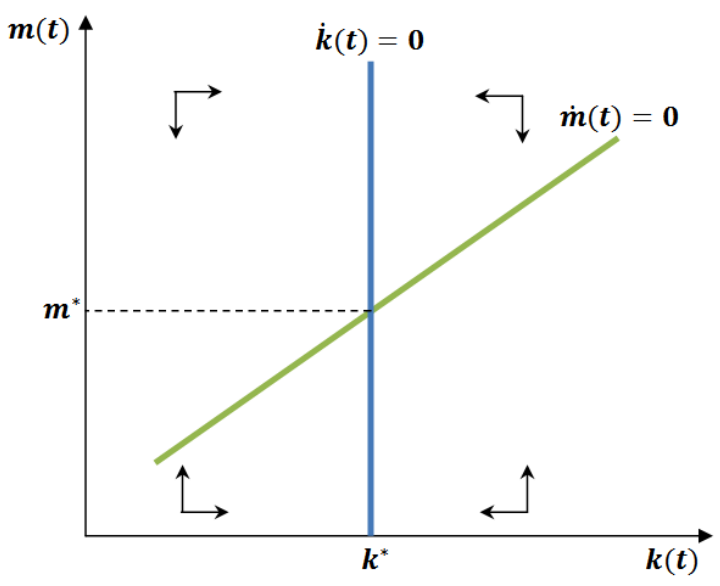

(a) Dynamics

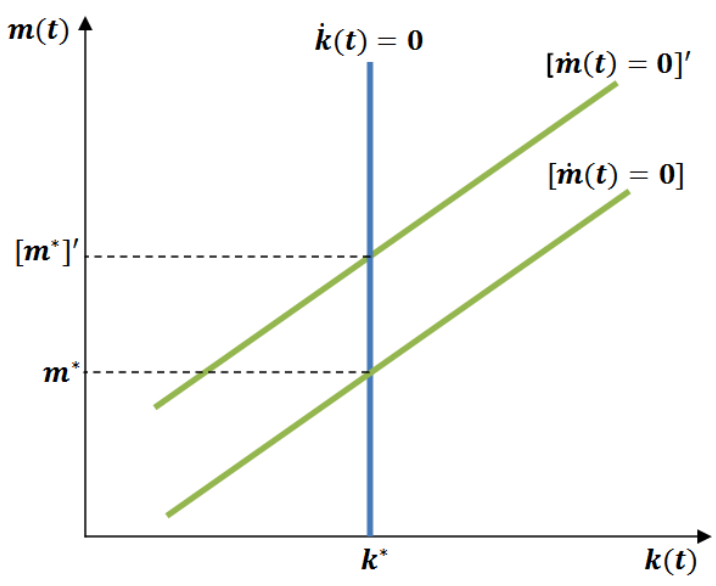

(b) A permanent change in $\dot{m}=0$

NoTE: $m(t)$ is stock market development and $k(t)$ is capital per capita.

For the a developed economy, the joint dynamics around $\dot{m}=0$ and $\dot{k}=0$ and the type of equilibrium depend on the slopes of the loci. In particular, if the slope of $\dot{k}=0$ is higher than the slope of $\dot{m}=0$, then the dynamic system is globally stable (Figure 5a), whereas it becomes a saddle path equilibrium if that inequality reverses (Figure 5b). In any of these cases, a permanent shock to stock market development has permanent effects on both $m(t)$ and $k(t)$. This prediction is consistent with general empirical findings for developed economies surveyed in Levine (2005).

Figure 5. Dynamic system for a developed country

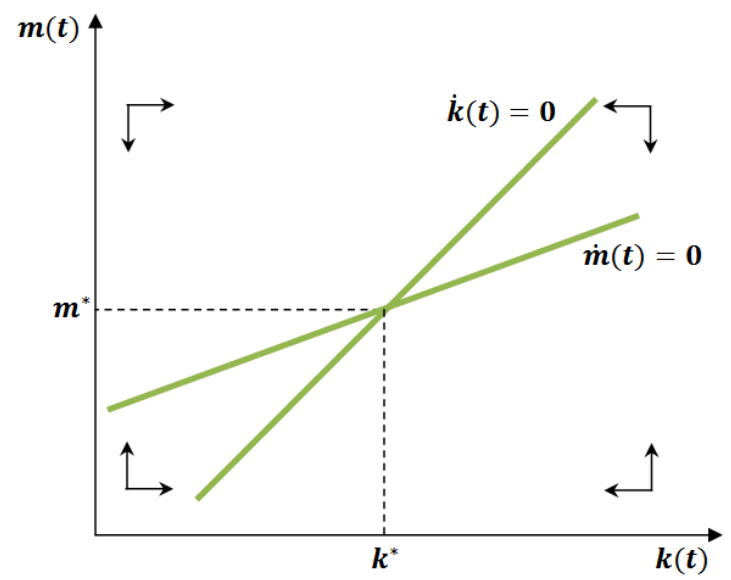

(a) Global stability

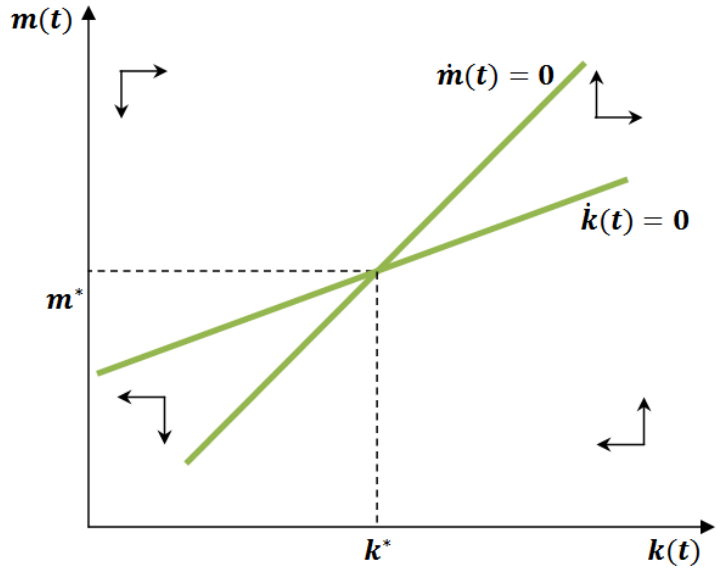

(b) Saddle path stability

NoTE: $m(t)$ is stock market development and $k(t)$ is capital per capita. 
In sum, this model predicts that any permanent shock to stock market development does not have any permanent effect on the level of output per capita in a developing economy. This result will be used in section 4 in order to empirically identify stock market shocks.

\section{Empirical model}

Consider the following bivariate VAR model of order $p$ :

$$
\begin{aligned}
& \Delta y_{t}=a_{10}+a_{11}^{(1)} \Delta y_{t-1}+a_{12}^{(1)} \Delta f_{t-1}+\cdots+a_{11}^{(p)} \Delta y_{t-p}+a_{12}^{(p)} \Delta f_{t-p}+d_{t}^{\prime} \alpha^{y}+\varepsilon_{t}^{y} \\
& \Delta f_{t}=a_{20}+a_{21}^{(1)} \Delta y_{t-1}+a_{22}^{(1)} \Delta f_{t-1}+\cdots+a_{21}^{(p)} \Delta y_{t-p}+a_{22}^{(p)} \Delta f_{t-p}+d_{t}^{\prime} \alpha^{f}+\varepsilon_{t}^{f}
\end{aligned}
$$

where $\Delta$ is the first-difference operator, $f_{t}$ is a real indicator of stock market development, $y_{t}$ is the log of real per capita output, $d_{t}$ is a column vector that contains dummy variables that account for specific events that are described below, and $\varepsilon_{t}^{y}$ and $\varepsilon_{t}^{f}$ are the corresponding error terms. The error terms are assumed to be normally distributed white noise processes, i.e. $\varepsilon_{t}^{j} \sim\left(0, \sigma_{\varepsilon^{j}}^{2}\right)$ and $\operatorname{Cov}\left(\varepsilon_{t}^{j}, \varepsilon_{s}^{j}\right)=0$ for $j=y, f$; however, the error terms between equations can be contemporaneously correlated, i.e. $\operatorname{Cov}\left(\varepsilon_{t}^{y}, \varepsilon_{t}^{f}\right) \neq 0$. According to Hamilton (1994, p. 651-654), if $y_{t}$ and $f_{t}$ are unit root processes and do not cointegrate (which is shown in section 5), then the VAR specification given by (1) and (2) is econometrically adequate to study the dynamic relationship between $y_{t}$ and $f_{t}$.

Based on the estimation of equations (1) and (2), we calculate impulse response functions (IRFs) and perform variance decomposition analysis. The IRFs describe the response of each variable to shocks that affect the dynamic system, whereas the variance decomposition provides the contribution of each shock to the fluctuations of each variable; however, the identification of structural shocks is a key ingredient for a meaningful analysis of IRFs and the variance decomposition. In our case, we are interested in the identification of stock market shocks.

In this paper we identify stock market shocks using the approach proposed by Blanchard and Quah (1989) and the predictions of the theoretical model discussed in section 3. Blanchard and Quah (1989) shows that in a bivariate VAR the structural shocks can be identified from the VAR (reduced-form) residuals by imposing one long-run restriction in the dynamic response of one variable. In our case, the long-run restriction required for identification of a stock market shock is provided by the theoretical model: in a developing economy (such as Peru), an exogenous change in stock market development has no long-run effects on real output per capita.

To see this formally, consider the moving-average representation of the VAR given by equations (1) and (2) (omitting intercepts) which can be written as follows: ${ }^{11}$

\footnotetext{
${ }^{11}$ The model satisfies the required assumptions for the validity of this identification approach, as in Quah and Vahey (1995): $\log$ output is integrated of order $1, \log \left(Y_{t}\right) \sim I(1)$, and the change in financial indicators is stationary, $\Delta f_{t} \sim I(0)$. The corresponding unit root tests are shown in Appendix A.
} 


$$
\left[\begin{array}{l}
\Delta y_{t} \\
\Delta f_{t}
\end{array}\right]=\left[\begin{array}{ll}
C_{11}(L) & C_{12}(L) \\
C_{21}(L) & C_{22}(L)
\end{array}\right]\left[\begin{array}{l}
u_{1, t} \\
u_{2, t}
\end{array}\right]
$$

where $u_{1, t}$ and $u_{2, t}$ represent structural error terms with a covariance matrix $\Sigma_{s}$ equal to the identity matrix $I$ (i.e. they are orthogonal), and each $C_{i j}(L)$ represents an infinite polynomial in the lag operator $L$ (e.g. $C_{12}(L)=c_{21}(0) L^{0}+c_{21}(1) L^{1}+c_{21}(2) L^{2}+\cdots$ ). If we want to interpret $u_{2, t}$ as a stock market shock, then we need to impose the following long-run restriction on the moving average representation:

$$
C_{12}(1) \equiv \sum_{i=0}^{\infty} c_{12}(i)=0
$$

which assures that $u_{2, t}$ does not have long run effects on the level of real output per capita. Given that the model does not impose any other restriction in the long-run response of $\Delta y_{t}$ or $\Delta f_{t}$ to any exogenous event, the terms $C_{11}(1), C_{21}(1)$ and $C_{22}(1)$ are left unrestricted; this means that $u_{2, t}$ may have long-run effects on any stock market indicator (i.e., $C_{22}(1) \neq 0$ ), and that $u_{1, t}$ may have permanent effects on both stock market indicators and real output per capita (i.e., $C_{11}(1) \neq 0$ and $C_{21}(1) \neq 0$ ). Furthermore, all short-run dynamics are left unrestricted.

As described in section 2, the Peruvian stock market is at an early stage of development which means that the long-run restriction given by (3) is reasonable. Furthermore, major shifts in the level of real GDP per capita have not been associated with particular events originating in the stock market, but have been mostly related to adverse weather shocks (e.g. "El Niño" weather phenomenon) and external events (both real and financial), among the most important ones. In order to control for these major events, we include exogenous additive dummy variables to the VAR, ${ }^{12}$ so that $u_{2, t}$ represents shocks that have no long-run effect on real output per capita.

However, as it was noted in section 3 , it is possible that $u_{2, t}$ is driven not only by stock market shocks but by other type of shocks with similar effects on real output, such as bank credit shocks. In fact, $u_{2, t}$ can be viewed as an "average" of all possible shocks that have no long-run effect on real economic activity but may have long-run effects on the stock market, one of which is a "true" exogenous stock market shock. ${ }^{13}$ Therefore, $u_{2, t}$ would be a noisy measure of stock market shocks. Given this, one possible strategy to get a better empirical approximation of stock market shocks is to extend the VAR by including a real indicator of the banking sector development, closely related to stock markets. We choose the ratio $b_{t}=$ credit/GDP which is a standard indicator in the literature. In this case, the moving average representation of the dynamic relationship

\footnotetext{
${ }^{12}$ The dummy variables are defined for the following events: "El Niño" phenomenon in 1983 and 1998, hyperinflation 1988-1990, the beginning of the private pension system in 1993, the 1997-1998 financial crisis, and the global financial crisis that emerged in 2008.

${ }^{13}$ Given the orthogonality assumption between $u_{1, t}$ and $u_{2, t}$, all shocks whose possible long-run effect on output cannot be discarded are represented by $u_{1, t}$. Thus, $u_{1, t}$ can also be viewed as an average of technological, preferences, government, factor prices, and consumption shocks, among the most important. For this reason, we do not impose any "label" on $u_{1, t}$.
} 
between $\Delta y_{t}, \Delta b_{t}$, and $\Delta f_{t}$ can be written as:

$$
\left[\begin{array}{c}
\Delta y_{t} \\
\Delta b_{t} \\
\Delta f_{t}
\end{array}\right]=\left[\begin{array}{lll}
C_{11}(L) & C_{12}(L) & C_{13}(L) \\
C_{21}(L) & C_{22}(L) & C_{23}(L) \\
C_{31}(L) & C_{32}(L) & C_{33}(L)
\end{array}\right]\left[\begin{array}{l}
u_{1, t} \\
u_{2, t} \\
u_{3, t}
\end{array}\right]
$$

Following the same reasoning as before, if we want to interpret $u_{3, t}$ as a stock market shock then we need to assume that it has no long-run effects on either $\Delta y_{t}$ or $\Delta b_{t}$, i.e. $C_{13}(1) \equiv \sum_{i=0}^{\infty} c_{13}(i)=0$ and $C_{23}(1) \equiv \sum_{i=0}^{\infty} c_{23}(i)=0$. The restriction $C_{13}(1) \equiv 0$ is similar to the restriction $C_{12}(1)=0$ imposed in the two-variable VAR and is consistent with the predictions of the theoretical model, whereas $C_{23}(1)=0$ implies that stock market shocks do not have long-run effects on banking sector development, an assumption that is supported by the Peruvian experience discussed in section 2. In addition, and in order to achieve exact identification, we also impose the restriction $C_{12}(1) \equiv \sum_{i=0}^{\infty} c_{12}(i)=0$ which states that $u_{2, t}$ represents shocks that do not have longrun effects on real output per capita. ${ }^{14}$ Under these restrictions, $u_{3, t}$ can be treated as a better approximation of stock market shocks.

In developing economies such as Peru, terms of trade has played an important role in macroeconomic performance (e.g. Mendoza, 1995; Kose, 2002; Broda, 2003, among others). This suggests that stock market shocks identified from the two-variable VAR, $u_{2, t}$, and from the three-variable VAR, $u_{3, t}$, may also be driven by external factors. Given this possibility, we also estimate VARs that include terms of trade, real output per capita, and stock market indicators, and identify stock market shocks $u_{3, t}$ following the same procedure as in the case with bank credit.

Once stock market shocks are identified in each case, we use IRFs and variance decomposition analysis in order to quantify the effects of the Peruvian stock market development in the dynamics of economic growth.

\section{Results}

The historical evolution of the Peruvian stock market described in section 2 suggests that the relationship between stock market development and real economic activity has not been the same during the period 1965-2013. Thus, based on well-known important political and economic events, the empirical analysis is performed for three sub-samples: (i) 1965-1990, which covers the initial development of stock markets in Peru, political and economic unstable episodes, and a period of increasing inflation that ended up in a hyperinflation episode between 1988 and 1990, (ii) 1991-2013, which covers the period of structural macroeconomic reforms, macroeconomic stability and low inflation, and (iii) 1965-2013 (the full sample).

\footnotetext{
${ }^{14}$ Notice that the validity of this restriction affects the interpretation of $u_{2, t}$; however, this is not a concern given that our focus is on stock market shocks represented by $u_{3, t}$ in this three-variable VAR. Therefore, we do not label $u_{2, t}$.
} 
In order to assess whether equations (1) and (2) represent a valid VAR specification, we test for the existence of unit roots in the series and the possibility of cointegration. We use the Augmented Dickey-Fuller (ADF) test (Dickey and Fuller, 1979) and the efficient DF-GLS (Elliot, Rothenberg and Stock, 1996) to test for unit root; the results shown in Appendix A indicate that the unit root hypothesis cannot be rejected. Cointegration between real output per capita and each stock market indicator was tested using Johansen's rank test; the results shown in Appendix B do not suggest evidence of cointegration. Thus, given the non-stationarity of the series and the lack of cointegration, we proceed with the estimation of VAR models of the form (1) and (2) for each stock market indicator.

Each VAR is estimated using maximum likelihood and the lag length is chosen with the sequential Likelihood Ratio (LR) test. Residual analysis is based on standard diagnostic tests which suggest that the chosen VARs are characterised by well-behaved error terms, i.e. homoskedastic, serially uncorrelated, and normally distributed. As it was discussed in section 4, we identify stock market shocks by imposing long-run restrictions on the impulse-response functions of each estimated VAR.

First, we analyse bivariate VARs and identify $u_{2, t}$ as a stock market shock imposing the restriction that $u_{2, t}$ does not have long-run effects on real GDP per capita, i.e. $C_{12}(1) \equiv \sum_{i=0}^{\infty} c_{12}(i)=0$. Figure 6 shows the cumulative response of real GDP per capita to a stock market shock ${ }^{15}$ and the corresponding $90 \%$ confidence intervals, for each stock market indicator ${ }^{16}$ and each sub-sample. ${ }^{17}$ The structural IRFs show that the response of real GDP per capita to a stock market shock has changed over time and has become relatively more important in recent years. In particular, stock market shocks do not have any statistically significant effect on real output for the sub-sample 1965-1990 or the full sample 1965-2013; however, for the sample 1991-2013 stock market shocks have a statistically significant effect on real output per capita, achieving the maximum effect after one year: $1.0 \%$ for value traded, $1.4 \%$ for turnover, and $1.0 \%$ for stock market capitalization.

The variance decomposition shown in the first block of Table 2 (Baseline VAR) indicates that the contribution of stock market shocks $u_{2, t}$ to the fluctuations in real output growth $\Delta y$ has also changed over time. In particular, the contribution of $u_{2, t}$ doubled from the sample 1965-1990 to the sample 1991-2013 (from $4.8 \%$ to $12.9 \%$ for the case of value traded, and from $10.8 \%$ to $21.7 \%$ for the case of turnover); however, the size of the contribution has not been very important in terms of magnitude (the maximum contribution is less than $22 \%$ ). In the case of stock market indicators, the contribution of stock market shocks $u_{2, t}$ has been much more important, especially during the sub-sample 1965-1990; this result can be interpreted as evidence that stock market fluctuations has become more less independent of real economic activity. Therefore, although stock market shocks have had a statistically significant short-run impact on

\footnotetext{
${ }^{15}$ The size of the shock is equal to a one-standard deviation.

${ }^{16}$ Data for market capitalization are only available from 1990.

${ }^{17}$ As a reference, Figure A-1 in Appendix C displays the impulse-response functions based on Cholesky decomposition.
} 
Figure 6. Cumulative output response to a positive stock market shock: long-run restrictions.

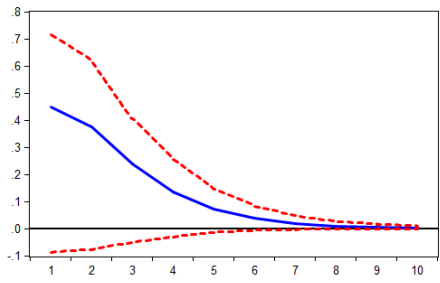

(a) Value traded (1965-2013)

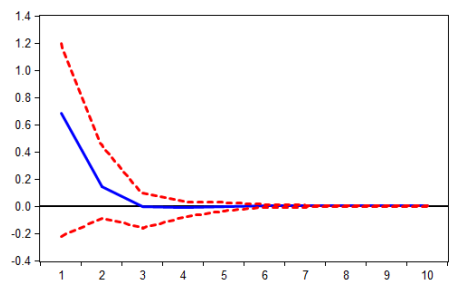

(d) Value traded (1965-1990)

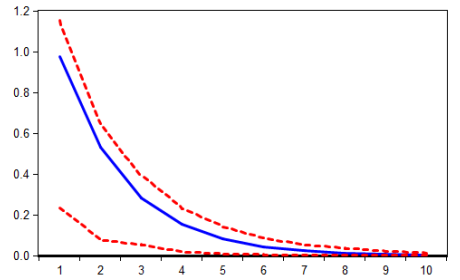

(g) Value traded (1991-2013)

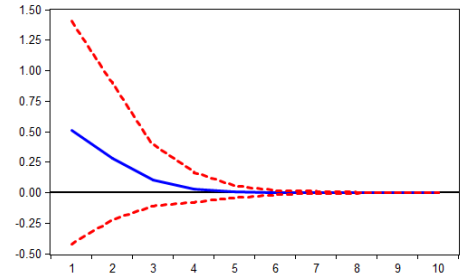

(b) Turnover (1965-2013)

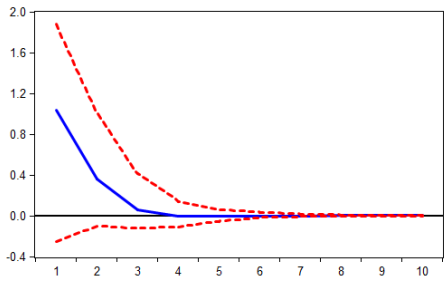

(e) Turnover (1965-1990)

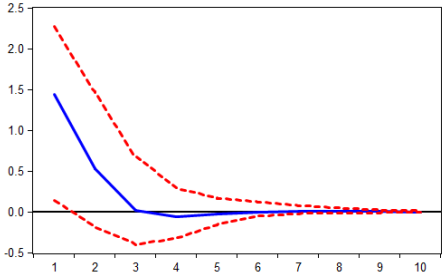

(h) Turnover (1991-2013)

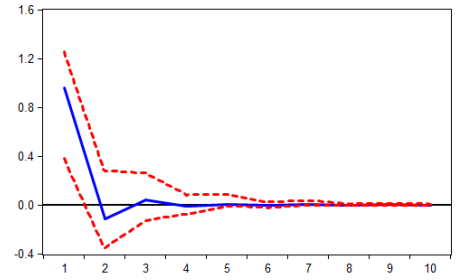

(c) Capitalization (1991-2013)

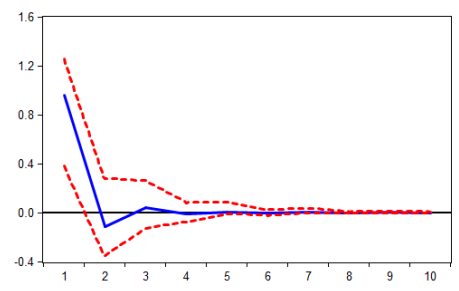

(f) Capitalization (1991-2013)

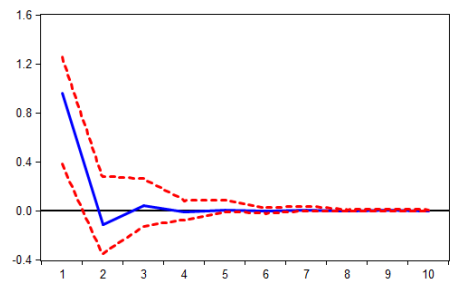

(i) Capitalization (1991-2013)

Note: The size of the shock is equal to one standard deviation. The vertical axis is measured in percent. Market capitalization data are available only from 1991. The impulse response functions display bootstrapped 90\% confidence intervals.

real economic activity after 1991, its relevance for growth fluctuations has remained at low levels.

Figure 7 shows the dynamic response of real GDP per capita to stock market shocks from three-variable VARs that include banking credit/GDP, a real indicator of banking sector development, whereas the second block of Table 2 displays the corresponding variance decomposition. The results, which are similar to the ones obtained with the two-variable VAR specifications, indicate that a stock market shock has a statistically significant effect on real GDP per capita only for the sample 1991-2013. In all cases, the maximum effect is achieved one year after the shock occurs and is equal to $1.0 \%$ for value traded/GDP, $1.1 \%$ for turnover, and $0.8 \%$ for capitalization. However, the contribution of stock market shocks to the fluctuations in economic growth has been very small in magnitude (the maximum contribution is $16.3 \%$ ); by sub-samples, the contribution was higher for the sub-sample 1991-2013 compared to the sub-sample 1965-2013. With 
Table 2. Contribution of stock-market shocks to the variance of output growth and stock markets indicators.

\begin{tabular}{|c|c|c|c|c|c|c|c|}
\hline \multirow{3}{*}{\multicolumn{2}{|c|}{ Horizon }} & \multicolumn{6}{|c|}{ Stock market indicators } \\
\hline & & \multicolumn{2}{|c|}{ Value traded } & \multicolumn{2}{|c|}{ Turnover } & \multicolumn{2}{|c|}{ Capitalization } \\
\hline & & $\Delta y$ & $\Delta f$ & $\Delta y$ & $\Delta f$ & $\Delta y$ & $\Delta f$ \\
\hline \multicolumn{8}{|c|}{ Baseline VAR } \\
\hline Sample & 1 year & 1.8 & 88.0 & 2.1 & 89.8 & n.a. & n.a. \\
\hline \multirow[t]{2}{*}{$1965-2013$} & 2 years & 1.6 & 90.0 & 2.3 & 89.0 & n.a. & n.a. \\
\hline & 10 years & 1.9 & 90.7 & 2.5 & 88.0 & n.a. & n.a. \\
\hline \multirow{3}{*}{$\begin{array}{l}\text { Sample } \\
1965-1990\end{array}$} & 1 year & 3.6 & 61.6 & 8.5 & 76.2 & n.a. & n.a. \\
\hline & 2 years & 4.7 & 55.5 & 10.2 & 76.0 & n.a. & n.a. \\
\hline & 10 years & 4.8 & 55.0 & 10.8 & 75.6 & n.a. & n.a. \\
\hline \multirow{3}{*}{$\begin{array}{l}\text { Sample } \\
1991-2013\end{array}$} & 1 year & 10.5 & 71.2 & 18.7 & 25.2 & 10.3 & 58.1 \\
\hline & 2 years & 12.2 & 70.0 & 20.3 & 30.6 & 15.6 & 54.8 \\
\hline & 10 years & 12.9 & 69.7 & 21.7 & 30.6 & 15.7 & 54.7 \\
\hline \multicolumn{8}{|c|}{ VAR with bank credit } \\
\hline Sample & 1 year & 1.2 & 91.0 & 1.4 & 88.3 & n.a. & n.a. \\
\hline \multirow[t]{2}{*}{$1965-2013$} & 2 years & 1.3 & 90.4 & 1.4 & 86.9 & n.a. & n.a. \\
\hline & 10 years & 1.4 & 88.4 & 1.6 & 85.8 & n.a. & n.a. \\
\hline \multirow{3}{*}{$\begin{array}{l}\text { Sample } \\
1965-1990\end{array}$} & 1 year & 0.3 & 66.1 & 9.3 & 72.3 & n.a. & n.a. \\
\hline & 2 years & 0.8 & 27.7 & 10.5 & 72.2 & n.a. & n.a. \\
\hline & 10 years & 0.7 & 27.5 & 10.8 & 71.6 & n.a. & n.a. \\
\hline \multirow{3}{*}{$\begin{array}{l}\text { Sample } \\
1991-2013\end{array}$} & 1 year & 11.8 & 66.3 & 12.9 & 11.4 & 7.3 & 74.0 \\
\hline & 2 years & 13.2 & 63.1 & 16.4 & 13.0 & 11.7 & 69.2 \\
\hline & 10 years & 14.1 & 61.3 & 16.3 & 12.9 & 11.8 & 69.2 \\
\hline \multicolumn{8}{|c|}{ VAR with terms of trade } \\
\hline Sample & 1 year & 1.4 & 84.8 & 1.4 & 87.8 & n.a. & n.a. \\
\hline \multirow[t]{2}{*}{$1965-2013$} & 2 years & 1.1 & 85.9 & 1.3 & 86.1 & n.a. & n.a. \\
\hline & 10 years & 1.3 & 86.7 & 1.4 & 84.0 & n.a. & n.a. \\
\hline \multirow{3}{*}{$\begin{array}{l}\text { Sample } \\
\text { 1965-1990 }\end{array}$} & 1 year & 5.6 & 40.3 & 6.5 & 69.2 & n.a. & n.a. \\
\hline & 2 years & 6.0 & 36.8 & 6.1 & 66.7 & n.a. & n.a. \\
\hline & 10 years & 6.1 & 36.1 & 6.9 & 65.9 & n.a. & n.a. \\
\hline \multirow{3}{*}{$\begin{array}{l}\text { Sample } \\
\text { 1991-2013 }\end{array}$} & 1 year & 8.7 & 49.2 & 16.1 & 21.0 & 5.9 & 46.0 \\
\hline & 2 years & 9.5 & 52.8 & 16.6 & 25.6 & 9.9 & 37.8 \\
\hline & 10 years & 10.1 & 54.4 & 17.9 & 25.8 & 9.6 & 37.7 \\
\hline
\end{tabular}

Note: The results are based on the estimation of three variable VARs that includes the growth rate of real output per capita and stock market indicators. The model with bank credit considers bank credit to GDP ratio. The model with terms of trade considers the growth rate of terms of trade. 
respect to the fluctuations in stock stock market development, the contribution of stock market shocks to value traded fluctuations increases from the first to the second subsample, whereas it decreases for the case of turnover.

Figure 7. Cumulative output response to a positive stock market shock: long-run restrictions and banking credit.

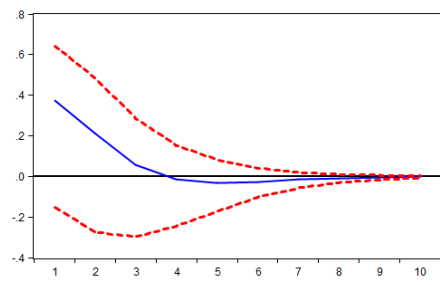

(a) Value traded (1965-2013)

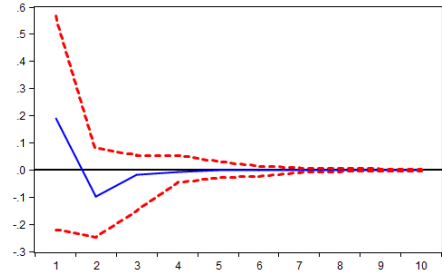

(d) Value traded (1965-1990)

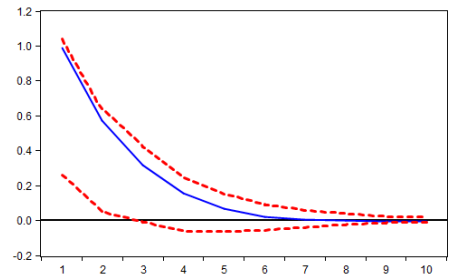

(g) Value traded (1991-2013)

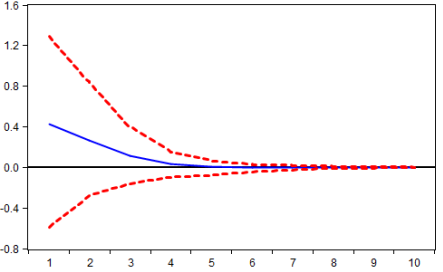

(b) Turnover (1965-2013)

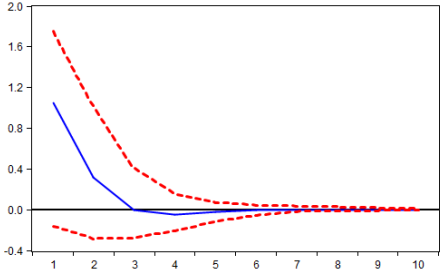

(e) Turnover (1965-1990)

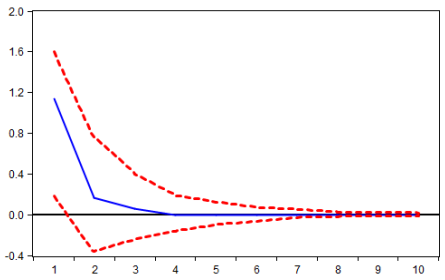

(h) Turnover (1991-2013)

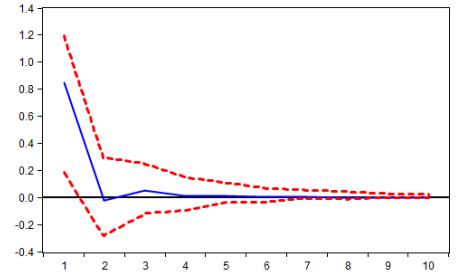

(c) Capitalization (1991-2013)

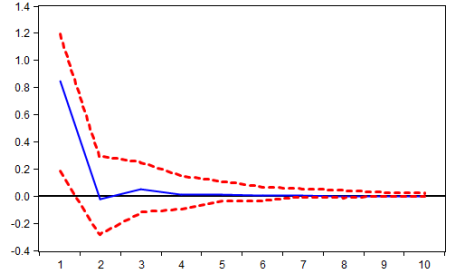

(f) Capitalization (1991-2013)

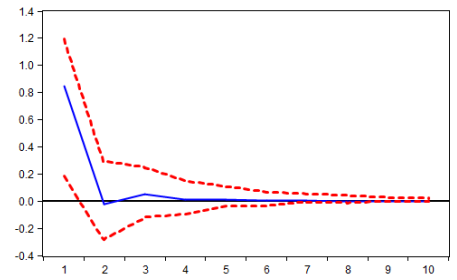

(i) Capitalization (1991-2013)

Note: The size of the shock is equal to one standard deviation. The vertical axis is measured in percent. Market capitalization data are available only from 1991. The impulse response functions display bootstrapped 90\% confidence intervals.

In addition, we extend the baseline VAR by including the growth rate of terms of trade. Figure 8 shows the corresponding IRFs of real GDP per capita to shocks in $u_{3, t}$, whereas the third block of Table 2 (VAR with terms of trade) displays the variance decomposition. Again, the results suggests that stock market shocks have had statistically significant effects only after 1991 but its contribution to output growth dynamics has been small. The IRFs show that the maximum effect is achieved one year after the shock occurs and is equal to $0.9 \%$ for value traded/GDP, $1.3 \%$ for turnover, and $0.8 \%$ for capitalization. However, the variance decomposition analysis indicate that the contribution of stock market shocks to the fluctuations in economic growth has been very small in magnitude (the maximum contribution is $17.9 \%$ ); by sub-samples, in all cases the contribution was higher for the sub-sample 1991-2013 compared to the sub- 
sample 1965-2013. With respect to the fluctuations in stock stock market development, the contribution of stock market shocks to value traded fluctuations increases from the first to the second sub-sample, whereas it decreases for the case of turnover.

Figure 8. Cumulative output response to a positive stock market shock: long-run restrictions and terms of trade.

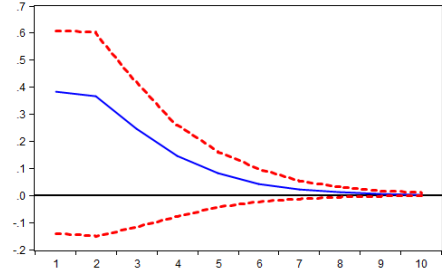

(a) Value traded (1965-2013)

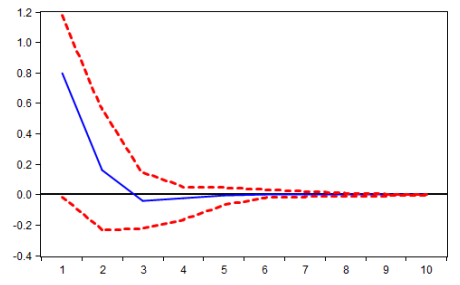

(d) Value traded (1965-1990)

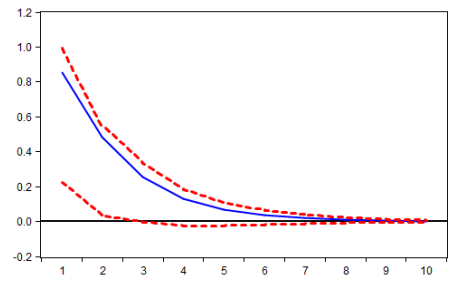

(g) Value traded (1991-2013)

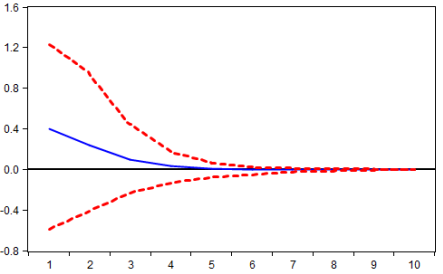

(b) Turnover (1965-2011)

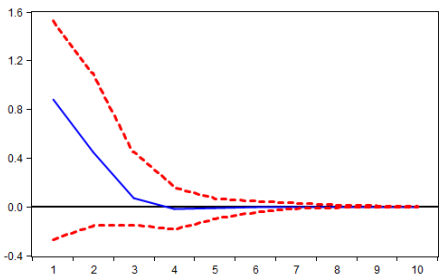

(e) Turnover (1965-1990)

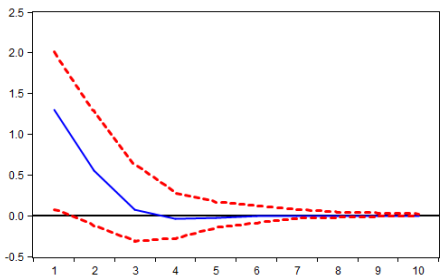

(h) Turnover (1991-2013)

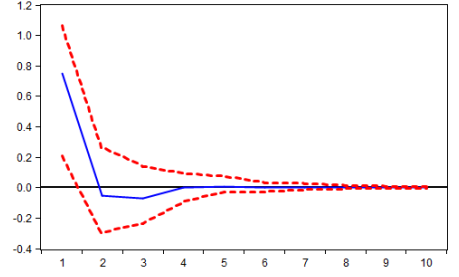

(c) Capitalization (1991-2013)

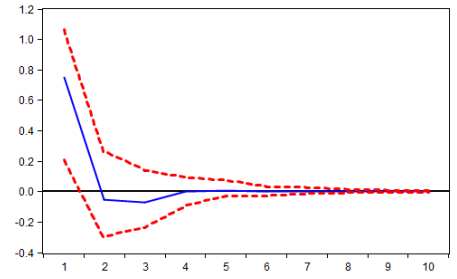

(f) Capitalization (1991-2013)

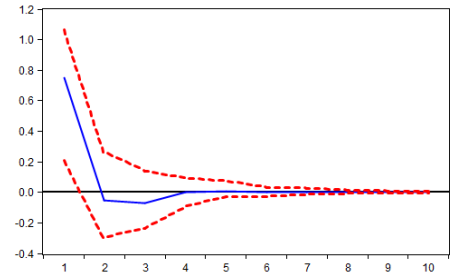

(i) Capitalization (1991-2013)

Note: The size of the shock is equal to one standard deviation. The vertical axis is measured in percent. Market capitalization data are available only from 1991. The impulse response functions display bootstrapped 90\% confidence intervals.

Finally, we apply standard Granger causality tests to each VAR specification in order to investigate the empirical causal relationship between the change in stock market development and output growth. As it is well-known, Granger causality provides information about the ability of one variable (or a group of variables) to forecast another variable (i.e. empirical causal relationship or time precedence), which does not necessarily coincides with true causation (Hamilton, 1994). The results shown in Table 3 indicate that Granger causality has changed over time. In all cases, news in the stock market indicator do Granger cause real output growth in the sub-sample 1991-2013 but not in the sample 1965-1990, a result that is in line with the results provided by the IRFs; finally, there is evidence that real output growth Granger causes value traded only in the sub-sample 1965-1990. 
Table 3. Granger causality tests.

\begin{tabular}{|c|c|c|c|}
\hline & 1965-2013 & 1965-1990 & 1991-2013 \\
\hline \multicolumn{4}{|l|}{ Baseline VAR } \\
\hline$\Delta V T \sim G C \quad \Delta y$ & 0.09 & 0.37 & 0.01 \\
\hline$\Delta y \sim G C \quad \Delta V T$ & 0.43 & 0.03 & 0.99 \\
\hline$\Delta T \sim G C \Delta y$ & 0.48 & 0.27 & 0.06 \\
\hline$\Delta y \sim G C \Delta T$ & 0.04 & 0.28 & 0.36 \\
\hline$\Delta C \sim G C \Delta y$ & n.a & n.a & 0.01 \\
\hline$\Delta y \sim G C \Delta C$ & n.a & n.a. & 0.65 \\
\hline \multicolumn{4}{|c|}{ VAR with bank credit } \\
\hline$\Delta V T \sim G C \Delta y$ & 0.13 & 0.75 & 0.00 \\
\hline$\Delta y \sim G C \Delta V T$ & 0.57 & 0.26 & 0.83 \\
\hline$\Delta T \sim G C \Delta y$ & 0.57 & 0.24 & 0.04 \\
\hline$\Delta y \sim G C \Delta T$ & 0.07 & 0.28 & 0.59 \\
\hline$\Delta C \sim G C \Delta y$ & n.a & n.a & 0.01 \\
\hline$\Delta y \sim G C \Delta C$ & n.a & n.a. & 0.65 \\
\hline \multicolumn{4}{|c|}{ VAR with terms of trade } \\
\hline$\Delta V T \sim G C \quad \Delta y$ & 0.10 & 0.16 & 0.01 \\
\hline$\Delta y \sim G C \Delta V T$ & 0.28 & 0.03 & 0.83 \\
\hline$\Delta T \sim G C \quad \Delta y$ & 0.58 & 0.38 & 0.09 \\
\hline$\Delta y \sim G C \Delta T$ & 0.08 & 0.29 & 0.38 \\
\hline$\Delta C \sim G C \Delta y$ & n.a & n.a & 0.00 \\
\hline$\Delta y \sim G C \Delta C$ & n.a & n.a. & 0.71 \\
\hline
\end{tabular}

Note: $\Delta V T, \Delta T, \Delta C$, and $\Delta y$ denote the first difference of value traded/GDP, turnover, capitalization/GDP, and the growth rate of real GDP per capita. Granger causality tests are based on the estimation of bivariate VARs describing $\Delta y$ and each stock market indicator with 1 lag. The null hypothesis is that the left-hand side variable does not Granger cause the right-hand side variable.

\section{Conclusions}

Using annual time series data for 1965-2013, we estimate vector autoregressive models (VARs) and identify stock market shocks using long-run restrictions. We use GDP per capita and three financial indicators associated with stock markets: value traded/GDP, stock market capitalization/GDP and turnover ratio.

The results show that the dynamic relationship between real GDP per capita and the stock market in Peru has changed over time and that stock market shocks have had a short-run causal effect on real GDP per capita only after 1991, a result that is consistent with Granger causality tests; in particular, a one-standard deviation shock to value traded/GDP, turnover and capitalization/GDP increases real GDP per capita after one year by $1 \%, 1.4 \%$ and $1.0 \%$, respectively. However, the contribution of stock market shocks to output growth dynamics has been small. 
Overall, the results imply that policy actions aimed at further developing the Peruvian stock market (e.g. promoting a higher participation of both lenders and borrowers) will have a positive impact on the dynamics of economic growth. However, it is possible that above a given threshold of development, further improvements of stock markets might have adverse effects on output and growth volatility, a topic that merits additional research. 


\section{References}

Ang, James and Warwick McKibbin. 2007. "Financial liberalization, financial sector development and growth: evidence from Malaysia." Journal of Development Economics 84(1): 215-233.

Arestis, Philip, Demetriades, Panicos O., and Kul B. Luintel. 2001. "Financial development and economic growth: The role of stock markets." Journal of Money, Credit and Banking 33(1): 16-41.

Arrau, P. (2001). "Un necesario big-bang para el crecimiento", in H. Beyer and R. Vergara (eds.), Las Tareas Pendientes: Reformas Necesarias para el Salto al Desarrollo, Centro de Estudios Pblicos.

Bagehot, Walter. 1873. Lombard Street, 1962 ed. Irwin, Homewood, IL.

Beck, Thorsten and Ross Levine. 2004. "Stock markets, Banks, and Growth: Panel evidence." Journal of Banking and Finance 28(3): 423-442.

Becsi, Zsolt, and Ping Wang. 1997. "Financial Development and Growth." Economic Review Q4: 46-62.

Bernanke,Ben, Jean Boivin, and Piotr Eliasz. 2005. "Measuring the effects of monetary policy: A Factor-Augmented Vector Autoregressive (FAVAR) Approach." Quarterly Journal of Economics 120(1): 387-423.

Blanchard, Oliver, and Danny Quah. 1989. "The Dynamic Effects of Aggregate Demand and Supply Disturbances." American Economic Review 79(4): 655-73.

Broda, Christian. 2003. "Terms of Trade and Exchange Rate Regimes in Developing Countries." Journal of International Economics 63(1): 31-58.

Campbell, John, and Pierre Perron. 1991. "Pitfalls and opportunities: what macroeconomists should know about unit roots." In O. Blanchard and S. Fischer, eds., NBER macroeconomics annual. Cambridge, MA: MIT Press, 141-201.

Caporale, Guglielmo M., Howells, Peter, and Alaa M. Soliman. 2005. "Endogenous Growth Models and Stock Market Development: Evidence from four Countries." Review of Development Economics 9(2): 166-176.

Cochrane, John H. 1994. "Shocks". NBER Working Paper, No. 4689.

Cooray, Arusha. 2010. "Do stock markets lead to economic growth?" Journal of Policy Modeling 32(4): 448-460.

Daouk, Hazem and Anchada Charoenrook. 2005. "A Study of Market-Wide Short-Selling Restrictions." Available at SSRN: http://ssrn.com/abstract=687562orhttp:// dx.doi.org/10.2139/ssrn.687562

Demetriades, Panicos, and Khaled Hussein. 1996. "Does financial development cause economic growth? Time-series evidence from 16 countries." Journal of Development Economics 51(2): 387-411. 
Devereux, Michael B. and Gregor W. Smith. 1994. "International risk sharing and economic growth." International Economic Review 35(4): 535-550.

Diaz-Martinez, Miguel and Emmanuel Fragniere. 2012. Short selling and the problem of market maturity in Latin America. In: Gregoriou, G. N., ed. Handbook of Short Selling. Elsevier, pp. 353-364.

Dickey, David A., and Wayne A. Fuller. 1979). "Distribution of the Estimators for Autoregressive Time Series with a Unit Root." Journal of the American Statistical Association 74(386): 427-431.

Elliot, Graham, Thomas J. Rothenberg, and James H. Stock. 1996. "Efficient Tests for an Autoregressive Unit Root." Econometrica 64(4): 813-836.

Enisan, Akinlo A. and Akinlo O. Olufisayo. 2009. "Stock market development and economic growth: Evidence from seven sub-Sahara African countries." Journal of Economics and Business 61(2): 162-171.

Fisher, Irving. 1933. "The Debt-Deflation Theory of Great Depressions." Econometrica 1(1): $337-357$.

Gertler, Mark. 1988. "Financial structure and agregate economic activity: An overview." Journal of Money, Credit, and Banking 20(3): 559-588.

Gupta, Nandini and Kathy Yuan. 2009. "On the growth effect of stock market liberalizations." The Review of Financial Studies 22(11): 4715-4752.

Henry, Peter Blair. 2000. "Do stock market liberalizations cause investment booms?" Journal of Financial Economics 58(1-2): 301-334.

Hamilton, James. 1994. "Time Series Analysis." New Jersey, USA: Princeton Unversity Press.

King, Robert G., and Ross Levine. 1993. "Finance, Entrepreneurship, and Growth: Theory and Evidence." Journal of Monetary Economics 32(3): 513-542.

Kose, M. Ayhan. 2002. "Explaining Business Cycles in Small Open Economies: How Much Do World Prices Matter?" Journal of International Economics 56(2): 299-327.

Levine, Ross. 1991. "Stock Market, Growth, and Tax Policy." The Journal of Finance 46(4): 1445-1465.

Levine, Ross. 2005. "Finance and Growth: Theory and Evidence." In Handbook of Economic Growth, edited by Philippe Aghion and Steven Durlauf, 865-934, edition 1, vol. 1, Chapter 12. Elsevier.

Levine, Ross and Sara Zervos. 1998. "Stock Markets, Banks and Economic Growth." American Economic Review 88(3): 537-558.

Marques, Luís Miguel, José Alberto Fuinhas, and António Cardoso Marques. 2013. "Does the stock market cause economic growth? Portuguese evidence of economic regime change." Economic Modelling 32(C): 316-324. 
Mendoza, Enrique G. 1995. "The Terms of Trade, the Real Exchange Rate, and Economic Fluctuations." International Economic Review 36(1): 101-37.

Obstfeld, Maurice. 1994. "Risk-taking, global diversification, and growth." American Economic Review 85(5): 1310-1329.

Quah, Danny and Shaun P. Vahey. 1995. "Measuring core inflation." Economic Journal 105(432): 1130-1144.

Schumpeter, Joseph. 1912. "The Theory of Economic Development: An Inquiry into Profits, Capital, Credit, Interest, and the Business Cycle".

Smith, Adam. 1776. "An Inquiry into the Nature and Causes of the Wealth of Nations" W. Stahan and T. Cadell, London.

Stock, James H. 1994. "Unit Roots, Structural Breaks and Trend." In R. F. Engle and D. L. McFadden (Eds.) Handbook of Econometrics Vol. 4. Amsterdam: Elsevier, 2739-2841. 


\section{Appendix}

\section{A Unit Root tests}

Table A-1. Unit Root Tests:1965-2013

\begin{tabular}{lccccc}
\hline \hline & Statistic & $1 \%$ & $5 \%$ & $10 \%$ & \\
\hline & & & & & \\
ADF test & & & & & \\
$\quad$ Value Traded & -2.427 & -4.161 & -3.506 & -3.183 & \\
$\quad$ Turnover & -3.207 & -4.161 & -3.506 & -3.183 & $* * *$ \\
$\quad$ Capitalization & -1.585 & -4.468 & -3.645 & -3.261 & \\
$\quad$ Real output per capita & -0.324 & -4.171 & -3.511 & -3.186 & \\
$\quad$ Terms of trade & -0.125 & -4.171 & -3.511 & -3.186 & \\
& & & & & \\
DF-GLS test & & & & & \\
$\quad$ Value Traded & -2.520 & -3.770 & -3.190 & -2.890 & \\
$\quad$ Turnover & -1.379 & -3.770 & -3.190 & -2.890 & \\
$\quad$ Capitalization & -1.717 & -3.770 & -3.190 & -2.890 & \\
$\quad$ Real output per capita & -0.993 & -3.770 & -3.190 & -2.890 & \\
Terms of trade & -1.158 & -3.770 & -3.190 & -2.890 & \\
& & & & &
\end{tabular}

Note: Value traded, turnover and capitalization are expressed in percentages, whereas real output per capita and terms of trade are expressed in logs. The null hypothesis is the existence of a unit root. The results assume that the true model for each series includes an intercept and a time trend.

Table A-2. Unit Root Tests:1965-1990

\begin{tabular}{lccccc}
\hline \hline & Statistic & $1 \%$ & $5 \%$ & $10 \%$ & \\
\hline & & & & & \\
ADF test & & & & & \\
$\quad$ Value Traded & -3.349 & -4.374 & -3.603 & -3.238 & $* * *$ \\
Turnover & -1.391 & -4.374 & -3.603 & -3.238 & \\
$\quad$ Capitalization & n.a. & n.a. & n.a. & n.a. & \\
Real output per capita & -0.663 & -4.468 & -3.645 & -3.261 & \\
Terms of trade & -0.122 & -4.498 & -3.658 & -3.269 & \\
& & & & & \\
DF-GLS test & & & & & $* *$ \\
$\quad$ Value Traded & -3.494 & -3.770 & -3.190 & -2.890 & $* *$ \\
Turnover & -1.265 & -3.770 & -3.190 & -2.890 & \\
Capitalization & n.a. & n.a. & n.a. & n.a. & \\
Real output per capita & -1.321 & -3.770 & -3.190 & -2.890 & \\
Terms of trade & -1.330 & -3.770 & -3.190 & -2.890 & \\
& & & & & \\
\hline \hline
\end{tabular}

Note: Same as Table A-1. 
Table A-3. Unit Root Tests:1991-2013

\begin{tabular}{lcccc}
\hline \hline & Statistic & $1 \%$ & $5 \%$ & $10 \%$ \\
\hline ADF test & & & & \\
$\quad$ Value Traded & & & & \\
$\quad$ Turnover & -2.628 & -4.441 & -3.633 & -3.255 \\
$\quad$ Capitalization & -1.069 & -4.441 & -3.633 & -3.255 \\
$\quad$ Real output per capita & -1.569 & -4.498 & -3.658 & -3.269 \\
Terms of trade & -0.936 & -4.441 & -3.633 & -3.255 \\
& -2.136 & -4.441 & -3.633 & -3.255 \\
DF-GLS test & & & & \\
$\quad$ Value Traded & & & & \\
Turnover & -2.513 & -3.770 & -3.190 & -2.890 \\
Capitalization & -0.921 & -3.770 & -3.190 & -2.890 \\
$\quad$ Real output per capita & -1.712 & -3.770 & -3.190 & -2.890 \\
Terms of trade & -1.123 & -3.770 & -3.190 & -2.890 \\
& -2.008 & -3.770 & -3.190 & -2.890 \\
& & & & \\
\hline \hline
\end{tabular}

Note: Same as Table A-1. 


\section{B Johansen cointegration test}

Table A-4. Johansen rank test

\begin{tabular}{lllll}
\hline \hline Lags & Cointegrating vectors & Value t. & Turnover & Capital. \\
\hline Sample: $1965-2013$ & & & & \\
1 & $\mathrm{r}=0$ & 0.316 & 0.650 & n.a. \\
& $\mathrm{r}=1$ & 0.667 & 0.958 & n.a. \\
2 & $\mathrm{r}=0$ & 0.571 & 0.425 & n.a. \\
& $\mathrm{r}=1$ & 0.410 & 0.340 & n.a. \\
3 & $\mathrm{r}=0$ & 0.266 & 0.318 & n.a. \\
& $\mathrm{r}=1$ & 0.474 & 0.439 & n.a. \\
4 & $\mathrm{r}=0$ & 0.207 & 0.402 & n.a. \\
& $\mathrm{r}=1$ & 0.507 & 0.765 & n.a. \\
\hline
\end{tabular}

\begin{tabular}{|c|c|c|c|c|c|c|}
\hline \multicolumn{7}{|c|}{ Sample: 1965-1990 } \\
\hline \multirow[t]{2}{*}{1} & $\mathrm{r}=0$ & 0.122 & & 0.436 & & \\
\hline & $\mathrm{r}=1$ & 0.393 & & 0.342 & & \\
\hline \multirow[t]{2}{*}{2} & $\mathrm{r}=0$ & 0.148 & & 0.095 & & \\
\hline & $\mathrm{r}=1$ & 0.484 & & 0.038 & $*$ & $\mathrm{n}$. \\
\hline \multirow[t]{2}{*}{3} & $\mathrm{r}=0$ & 0.285 & & 0.007 & $*$ & n. \\
\hline & $\mathrm{r}=1$ & 0.776 & & 0.292 & & \\
\hline \multirow[t]{2}{*}{4} & $\mathrm{r}=0$ & 0.004 & $*$ & 0.032 & $*$ & n.a. \\
\hline & $\mathrm{r}=1$ & 0.520 & & 0.933 & & \\
\hline
\end{tabular}

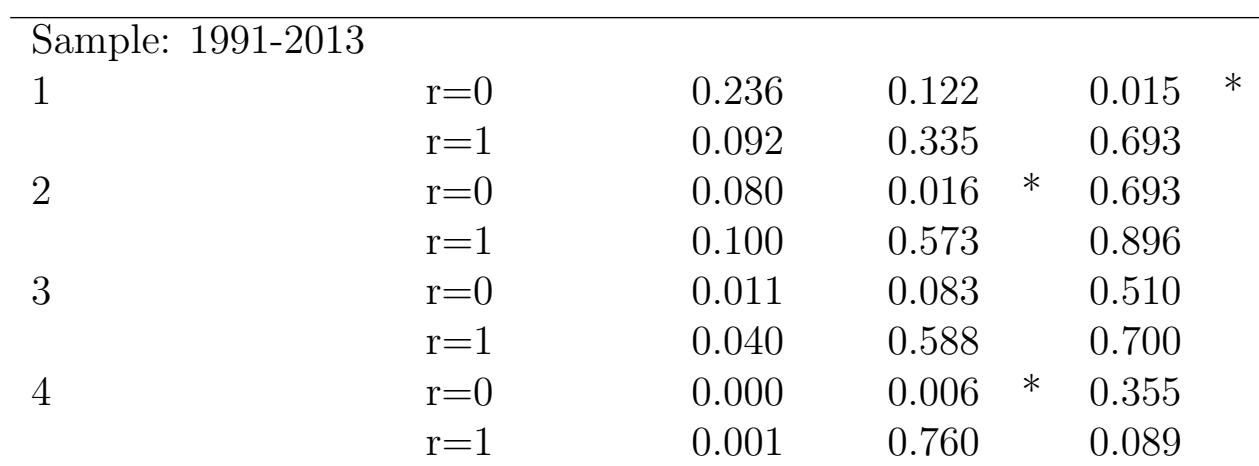

Note: Value traded, turnover and capitalization are expressed in percentages, whereas real output per capita is expressed in logs. The null hypothesis is the existence of " $r$ " cointegrating vectors. The entries represent the probability of rejecting the null hypothesis. In all cases it is assume that the data contain a time trend. Optimal lag length tests consider up to a maximum of 4 lags. 


\section{Impulse-response functions: Cholesky decompo- sition.}

Figure A-1. Cumulative output response to a positive stock market shock: Cholesky approach.

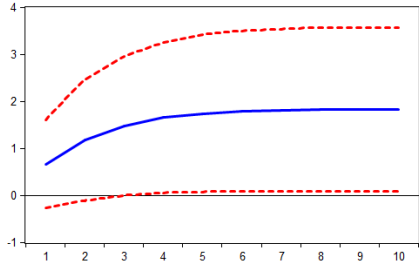

(a) Value traded (1965-2013)

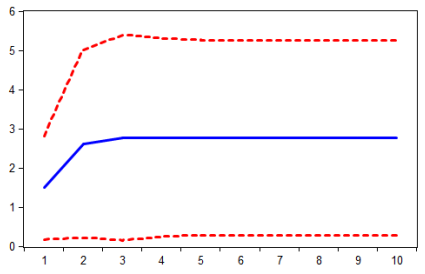

(d) Value traded (1965-1990)

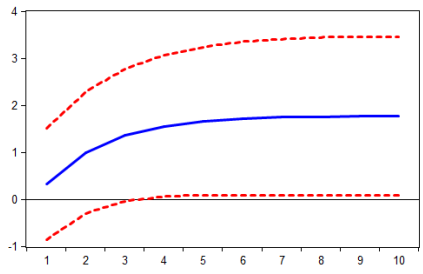

(g) Value traded (1991-2013)

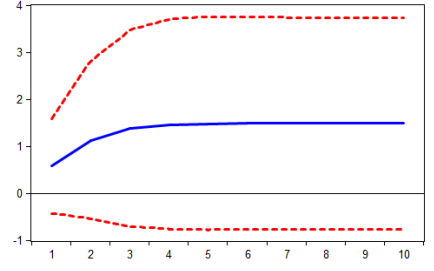

(b) Turnover (1965-2013)

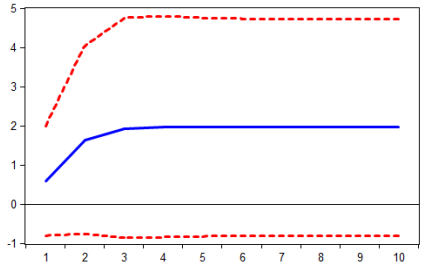

(e) Turnover (1965-1990)

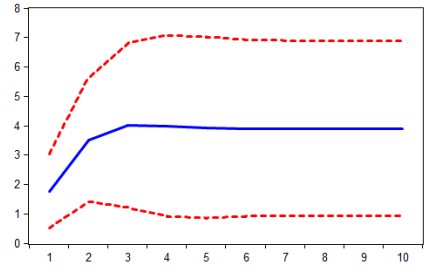

(h) Turnover (1991-2013)

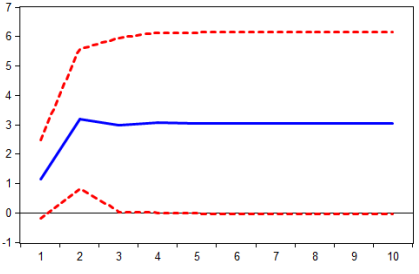

(c) Capitalization (1991-2013)

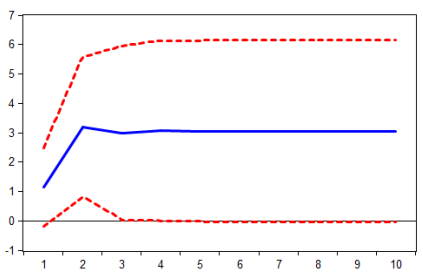

(f) Capitalization (1991-2013)

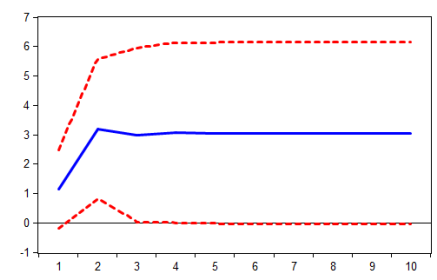

(i) Capitalization (1991-2013)

NOTE: The shock size is one standard deviation of the orthogonalized residual. The vertical axis is measured in percent. Market capitalization data are available from 1991.

Even though it is possible to estimate IRFs based on the original VAR innovations $\varepsilon_{t}^{y}$ and $\varepsilon_{t}^{f}$, they are not economically relevant because the innovations are correlated and thus cannot be attributed to any specific variable. The literature provides several alternatives to construct orthogonal innovations from the original VAR innovations. The basic and most popular of these procedures is called the Cholesky decomposition.

The Cholesky decomposition of the residual variance-covariance matrix is a standard procedure to decompose the original VAR innovations into a set of uncorrelated components or orthogonal errors. This procedure is based on the imposition of zero restrictions on the contemporaneous response of the variables to shocks coming from other variables in the VAR. As a result, the variables can be "ordered" from the most exogenous (i.e the one that does not respond contemporaneously to any shock except the one coming 
from itsself) to the less exogenous (i.e. the one that responds contemporaneously to all shocks in the system), which is usually referred to as "Cholesky ordering". For instance, a Cholesky ordering $\left(\Delta y_{t}, \Delta f_{t}\right)$ means that $\Delta y_{t}$ responds contemporaneously to surprises in $\Delta y_{t}$ only, whereas $\Delta f_{t}$ responds contemporaneously to surprises in both $\Delta y_{t}$ and $\Delta f_{t}$.

Under the Cholesky decomposition, the resulting IRFs describe the dynamic response of $\Delta y_{t}$ and $\Delta f_{t}$ to an orthogonalized shock in either $\Delta y_{t}$ or $\Delta f_{t}$. In particular, the response of $\Delta y_{t}$ to an orthogonalized shock in $\Delta f_{t}$ can be interpreted as the change in the forecast of $\Delta y_{t}$ due to "new information" about $\Delta f_{t}$. On the other hand, the variance decomposition provides the contribution of each orthogonalized shock, $u_{t}^{y}$ and $u_{t}^{f}$, to the fluctuations in $\Delta y_{t}$ and $\Delta f_{t}$. Furthermore, if $\Delta f_{t}\left(\Delta y_{t}\right)$ is mostly explained by its own shocks $u_{t}^{f}\left(u_{t}^{y}\right)$, then $\Delta f_{t}\left(\Delta y_{t}\right)$ can be considered as relatively exogenous. Figure A-1 shows the orthogonalised IRFs based on the Cholesky decomposition.

One important limitation of the Cholesky method is that results from IRFs and VD depend on the Cholesky ordering. However, if one particular ordering is "reasonable", then at least one of the orthogonalized shocks can be interpreted as a structural or primitive shock, i.e. a shock whose true origin could be known conditional on the VAR specification. ${ }^{18}$ However, in our case there does not seem to exist a unique reasonable Cholesky ordering: real activity might respond to a stock market shock within the same year the shock occurs, whereas it is almost certain that the stock market will react immediately to shocks in the real sector.

\footnotetext{
${ }^{18}$ This is the case, for example, in monetary policy analysis, where interest rate is ordered last. See for example Bernanke et al. (2005)
} 